\title{
Assessment of Factors Associated with the Effectiveness of Premarital Screening for Hemoglobinopathies in the South of Saudi Arabia
}

\author{
Ibrahim M Gosadi (D) \\ Gassem A Gohal ${ }^{2}$ \\ Alanoud E Dalak ${ }^{3}$ \\ Anas A Alnami ${ }^{3}$ \\ Norah A Aljabri ${ }^{3}$ \\ Atyaf J Zurayyir ${ }^{3}$ \\ 'Department of Family and Community \\ Medicine, Faculty of Medicine, Jazan \\ University, Jazan, Saudi Arabia; \\ ${ }^{2}$ Department of Pediatrics, Faculty of \\ Medicine, Jazan University, Jazan, Saudi \\ Arabia; ${ }^{3}$ Faculty of Medicine, Jazan \\ University, Jazan, Saudi Arabia
}

Purpose: Southern region of Saudi Arabia has one of the highest prevalence of sickle cell disease and thalassemia in the kingdom. This study aims to assess the factors associated with the rejection of premarital clinical counselling in the Jazan region.

Methods: This is a cross-sectional investigation conducted in the Jazan region of Saudi Arabia. The investigation targeted subjects who performed premarital screening and, with their screened partners, were identified as high-risk couples and proceeded with their marriage. Data were collected via a web-based self-administered questionnaire. A section of the questionnaire targeted those who attended the premarital counselling clinic in the Jazan region and assessed the factors that led to the rejection of premarital counselling advice.

Results: A total of 413 participants were recruited. The mean age of the respondents was 33 years, and the majority of the respondents were female $(62.5 \%)$. The majority of the respondents were related to their partners $(66.8 \%)$ and were carriers of sickle cell disease $(67.8 \%)$. Among the respondents, only 192 had attended premarital counselling clinics in the Jazan region. More than half of the attendees rejected the premarital counseling advice because they believed that their marriage was their unavoidable destiny. About 30\% of the attendees reported that disease complications were not well explained during the counselling. Thirtyfive attendees $(18.2 \%)$ proceeded with the marriage because they thought the risk of transmitting the disease to their children was small and 10 attendees $(5.2 \%)$ proceeded with their marriage because they believed their children's lives would not be affected by the disease.

Conclusion: The findings explain the limited influence of the premarital counselling advice in raising the awareness of the attendees about inherited blood disorders. The findings indicate a strong cultural influence leading to the reduced effectiveness of premarital counselling in the Jazan region.

Keywords: sickle cell, thalassemia, premarital, counselling, screening, Saudi Arabia

\section{Introduction}

Inherited hemoglobinopathies (sickle cell anaemia and thalassemia) are monogenic disorders that influence the functioning of red blood cells and the survival of affected patients. ${ }^{1,2}$ Hemoglobinopathies are prevalent in African, Middle Eastern and South Asian countries. ${ }^{3}$ Individuals affected with inherited hemoglobinopathies are at high risk of anaemia, infections, pain, and can suffer from cardiac, endocrine and pulmonary complications leading to frequent need for hospitalisation. ${ }^{4,5}$ Furthermore, the need to receive frequent blood transfusions may subject affected individuals to a higher risk of acquiring blood-borne disorders, such as hepatitis c. ${ }^{6}$
Correspondence: Ibrahim M Gosadi Department of Family and Community Medicine, Faculty of Medicine, Jazan University, P.O. Box: 2349, Jazan, 8262I, Saudi Arabia

Tel +966562/377II

Email gossady@hotmail.com 
Inherited hemoglobinopathies can be considered as endemic disorders in Saudi Arabia, where the endemicity has been explained by biological and cultural factors. ${ }^{7}$ As a method of primary prevention of sickle cell anaemia and thalassemia, the premarital screening programme (currently called the healthy marriage programme) was established in Saudi Arabia in 2004. The programme aims to identify risky couples who are either carriers or affected with inherited blood disorders and are at high risk of having children affected by the hemoglobinopathies. ${ }^{8}$

The published data currently available suggests that more than 3 million individuals have benefited from premarital screening in Saudi Arabia since its inception. ${ }^{8}$ Nonetheless, in a recent nationwide survey measuring awareness about premarital screening including a sample of 6263 participants, it was reported that only 575 (9.2\%) of the participants had satisfactory awareness level. ${ }^{9}$ Additionally, data concerning the number of couples who were identified as risky are limited. In a study reporting the six-year outcome of the premarital screening programme between 2004 and 2009, a total of 8925 were identified as risky couples. Among this identified cohort of risky couples, a sample of 5370 were followed up to learn about the cancellation of marriage proposals. The follow-up findings indicated that 3945 (73\%) of the risky couples ignored the screening results and proceeded with marriage. ${ }^{10}$

In 2015, the Saudi Ministry of Health published the Counselling Clinic Guidelines for Premarital Screening. The counselling clinics were established to provide health education services for risky couples about the potential clinical implications of their marriage and the risk of transmitting inherited blood disorders to their children. The guidelines were produced with the aim of enhancing overall communication skills between healthcare workers providing the counselling and the recipients of high-risk couples in order to enable informed decisions concerning whether to proceed or to cancel the marriage proposal. ${ }^{11}$

Regional variations in the prevalence of hemoglobinopathies in Saudi Arabia have been reported. According to Al-Saeed et al, the Eastern and Southern regions of Saudi Arabia have the highest prevalence of sickle cell disease and thalassemia. The marked regional variations suggest a need for better hemoglobinopathies preventive services allocation. ${ }^{12}$ Additionally, in a study assessing the prevalence of haemoglobin abnormalities among attendees of a single premarital screening centre in the Jazan region between January and October 2018, it was reported that among 3790 screened individuals, 1312 (28.5\%) were identified as having hemoglobinopathies. ${ }^{13}$ However, studies assessing the factors associated with the rejection of premarital clinical counselling in the Jazan region, in the south of Saudi Arabia, are currently lacking. This study aims to fill this gap of knowledge concerning a region with high prevalence of inherited blood disorders in comparison to other regions in the kingdom.

\section{Methods}

\section{Study Settings and Participants}

This study is a cross-sectional investigation conducted in the Jazan region of Saudi Arabia between April and June 2020. The investigation targeted subjects who performed premarital screening and, with their screened partners, were identified as high-risk couples and proceeded with their marriage. The process of performing premarital testing, including testing for hemoglobinopathies, identification of high-risk couples and genetic counselling services provision within the healthy marriage program is described elsewhere. ${ }^{8}$ Ethical approval to conduct the study was granted via the Standing Committee for Scientific Research Ethics in Jazan University (approval number REC 41/1-002). All the participants provided informed consent, and the study was conducted in accordance with the Declaration of Helsinki.

A convenient non-random sampling approach was utilised to recruit the study's participants. The study was advertised in the social media, including online media targeting patients with hemoglobinopathies in the region, with descriptions of the study's main objectives and of the targeted population. It was explained that participation was voluntary and included no collection of identification data. The respondents were included in the study if they had performed the premarital screening in the Jazan region, and were identified, with their partners, as high-risk couples. Participants who performed premarital screening outside the Jazan region were excluded. Due to difficulties related to accessing the study's population, the respondents were encouraged to share the web-link with acquaintances who were affected with hemoglobinopathies, to assist in reaching the required sample size.

The web-based questionnaire included contact information of the research team, enabling respondents requiring further clarification or assistance to contact the investigators before recruitment. At the time of the conception and design of the study, the number of couples 
who had benefited from the premarital screening services in the Jazan region was not publicly published. However, the study by Al Suliman et al included a sample of 129 risky individuals who proceeded with marriage. It was noted that the strongest influence was cultural pressure and this was reported by $48 \%$ of the study sample. ${ }^{14}$ Therefore, sample size calculation was dependent on the expected frequency of cultural pressure within a population in Saudi Arabia. A sample of 384 subjects was estimated using the formula for a prevalence assessment, $\mathrm{n}=([\mathrm{z} 2 \times \mathrm{p} \times \mathrm{q}]) / \mathrm{d} 2$, where $\mathrm{z}=95 \%$ confidence interval, $\mathrm{p}=48 \%, \mathrm{q}=1-\mathrm{p}, \mathrm{d}=$ error $\leq 5 \%$.

\section{Study Instrument and Measures}

Data were collected via a web-based self-administered questionnaire. The questionnaire was developed after consulting the relevant literature concerning factors that might influence the decision of high-risk couples to proceed with marriage. ${ }^{14}$ The questionnaire included sections related to the demographics of the participants, a history of hemoglobinopathies, transmission of hemoglobinopathies to their children, and the opinion of the participants about hemoglobinopathies. The final section of the questionnaire targeted those who attended the premarital counselling clinics in the Jazan region and assessed the factors that led to the rejection of premarital counselling advice.

The questionnaire included a combination of closedended and open-ended questions. The questionnaire was reviewed by consultants in epidemiology and paediatric haematology to assess the comprehensiveness of the questionnaire in answering the study's questions. Additionally, the questionnaire was piloted in its web-based format on a sample of 10 participants to test its clarity and the time needed to complete the questionnaire.

\section{Data Analysis}

The statistical package for the social sciences (SPSS) (version 25) was used to conduct the statistical analysis. Binary and categorical data were analysed using frequencies and proportions. Continuous data was analysed via either means and standard deviations (SD) for normally distributed data or medians, and minimum and maximum values for skewed variables. Finally, open-ended responses to questions related to the reasons for rejecting the premarital counselling advice were screened by a single investigator (IG) and coded to enable the calculation of frequencies and the proportions of similar responses.

\section{Results}

\section{Summary of Study Participants}

A total of 441 responses were recorded. After reviewing the responses, 18 responses were excluded, since they performed premarital screening outside the Jazan region or were engaged and not yet married at the time of completing the questionnaire. Additionally, 10 cases were removed as they were identified as replicated entries. After identification of eligible participants, a total of 413 participants were recruited.

Table 1 illustrates the demographics of 413 respondents affected by hemoglobinopathies from the Jazan region who, with their partners, were identified as high-risk couples and proceeded with their marriages. The mean age of the respondents was 33 years, and the majority of the respondents were female $(62.5 \%)$. The majority of the respondents were married at the time of data collection (96.4\%) and were holders of a diploma or a bachelor degree. Finally, when the participants were asked about their employment, $29.5 \%$ of the respondents

Table I Demographics of 413 Respondents from the Jazan Region Who, with Their Partners, Were Identified as High-Risk Couples and Proceeded with Their Marriages

\begin{tabular}{|l|l|}
\hline Variables & \\
\hline Gender: Frequency [\%] & \\
Males & $155[37.5 \%]$ \\
Females & $258[62.5 \%]$ \\
\hline Age: Mean [SD] & $33[10.6]$ \\
\hline Marital Status: Frequency [\%] & \\
Married & $389[96.4 \%]$ \\
Divorced & $8[1.9 \%]$ \\
Widow & $5[1.2 \%]$ \\
Other & $2[0.5 \%]$ \\
\hline Education Level: Frequency [\%] & \\
No official education & $9[2.2 \%]$ \\
Elementary & $32[7.7 \%]$ \\
Intermediate & $20[4.8 \%]$ \\
Secondary & $105[25.4 \%]$ \\
Diploma/University & $223[54 \%]$ \\
Postgraduate & $24[5.8 \%]$ \\
\hline Employment Status: Frequency [\%] & \\
Student & $62[15 \%]$ \\
Governmental employee & $122[29.5 \%]$ \\
Military & $38[9.2 \%]$ \\
Private sector employees & $35[8.5 \%]$ \\
Housewife & $107[25.9 \%]$ \\
Unemployed/retired & $49[11.9 \%]$ \\
\hline
\end{tabular}


were governmental employees, and $25.9 \%$ were identified as housewives.

Table 2 illustrates the degree of relationship, prevalence and family history of hemoglobinopathies among the respondents. The majority of the respondents were related to their partners $(66.8 \%)$. A total of 176 responding parents were first-degree cousins of their partners $(43 \%)$, which may indicate cultural factors contributing to the decision of high-risk couples to proceed with marriage. The majority of the respondents were carriers of sickle cell disease $(67.8 \%)$ and had a family history of the same

Table 2 Degree of Relationship, Prevalence and Family History of Hemoglobinopathies Among 413 Responding Parents from the Jazan Region with Offspring Affected by Hemoglobinopathies

\begin{tabular}{|l|l|}
\hline Variable & $\begin{array}{l}\text { Frequency } \\
{[\%]}\end{array}$ \\
\hline $\begin{array}{l}\text { Degree of relationship between couple*: } \\
\text { First degree cousins (paternal side) } \\
\text { First degree cousins (maternal side) }\end{array}$ & $108[26.4 \%]$ \\
Second degree cousins & $68[16.6 \%]$ \\
Related to the same tribe & $37[9 \%]$ \\
No relationship & $59[14.4 \%]$ \\
\hline Disease identified among the participants & $137[33.2 \%]$ \\
Sickle cell disease (carrier) & \\
Sickle cell disease (affected) & $280[67.8 \%]$ \\
Thalassemia (carrier) & $66[16 \%]$ \\
Thalassemia (affected) & $58[14 \%]$ \\
\hline Participants with family history of the same identified & $273[65.3 \%]$ \\
disease* & \\
\hline
\end{tabular}

Notes: $* 4$ missing cases for degree of relationship, I missing case of family history of the same identified disease. identified disease $(65.3 \%)$. Finally, 282 respondents $(68 \%)$ reported having a minimum of one child affected by inherited hemoglobinopathies.

\section{Opinions and Source of Information About Hemoglobinopathies}

Opinions and sources of information concerning hemoglobinopathies among the responding participants are explained in Table 3. Sixty-three participants (15.3\%) declared that they would advise other high-risk couples to proceed with marriage. Additionally, 62 (15\%) participants believed that there was no association between consanguinity and the risk of having children affected with hemoglobinopathies. Thirty-five participants (8.7\%) believed that haemoglobinopathies are not prevalent in the Jazan region. Upon asking the participants about their main source of knowledge about inherited blood disorders, $22.5 \%$ of the participants declared that the Internet was their main source. Additionally, 15.6\% reported gaining information about inherited blood disorders via asking other individuals affected by hemoglobinopathies. Only 52 participants $(13.3 \%)$ declared that physicians or other healthcare workers were their source of information about hemoglobinopathies, which may indicate a limited contribution of healthcare workers in raising awareness about hemoglobinopathies in the region.

\section{Factors Associated with Refusal of Premarital Counselling}

Among the 413 respondents, only 192 had attended premarital counselling clinics in the Jazan region. The

Table 3 Opinions and Source of Information Concerning Hemoglobinopathies Among 413 Responding Parents from the Jazan Region with Offspring Affected by Hemoglobinopathies

\begin{tabular}{|l|l|}
\hline Variable & Frequency [\%] \\
\hline Opinions concerning hemoglobinopathies: & \\
Parents who would advise risky couples to proceed with marriage & $63[15.3 \%]$ \\
Parents who believe that there is no association between consanguinity and the risk of inherited blood disorders & $62[15 \%]$ \\
Parents who believe that inherited blood disorders are not prevalent in the Jazan region & $35[8.7 \%]$ \\
\hline Source of information about inherited blood disorders* & \\
Internet & $93[22.5 \%]$ \\
Physicians /healthcare workers & $52[13.3 \%]$ \\
From affected individuals & $7[15.6 \%]$ \\
Books/ pamphlets/journals & $30[7.2 \%]$ \\
During school/university studies & $9[2.1 \%]$ \\
TV & $3[0.7 \%]$ \\
\hline
\end{tabular}

Note: *Participants were able to select more than one answer. 
opinions of 192 attendees are summarised in Table 4. The majority $(85.7 \%)$ of the attendees reported that the risk of disease transmission to their children was explained during the counselling session. The average duration of the counselling session was 10 minutes. However, about $30 \%$ of the attendees reported that disease complications were not well explained during the counselling. The majority of the participants $(78.5 \%)$ declared that the counselling physicians were able to answer their queries about inherited blood disorders. Upon asking the participants about the educational materials that were provided during the counselling session, the majority of the respondents $(47.1 \%)$ declared that there were no materials provided and the session was limited to conversation with the attending physicians providing the counselling.
When the attendees were asked about their reasons for rejecting the counselling advice and proceeding with their marriage, more than half of the attendees reported that their marriage was their unavoidable destiny. Thirty-five attendees $(18.2 \%)$ proceeded with the marriage because they thought the risk of transmitting the disease to their children was small, 14 attendees $(7.3 \%)$ thought that the counselling was not convincing and 10 attendees $(5.2 \%)$ declared that they proceeded with their marriage because they believed their children's lives would not be affected by the disease. These notions explain the limited influence of the premarital counselling advice in raising the awareness of the attendees about inherited blood disorders in the region. Other social or financial factors were reported, such as having a relationship between the couples, paying

Table 4 Opinions Regarding Premarital Counselling Among 192 Participants Who Attended Premarital Counselling in the Jazan Region

\begin{tabular}{|c|c|c|}
\hline \multicolumn{2}{|l|}{ Variables } & \multirow{2}{*}{$\begin{array}{l}\text { Missing Cases } \\
15\end{array}$} \\
\hline Average duration of counselling session in minutes: median [minimum - maximum] & $10[<1-66]$ & \\
\hline Was risk of transmitting diseases explained: Frequency [\%] & & 2 \\
\hline Yes & $162[85.7 \%]$ & \\
\hline No & $27[14.3 \%]$ & \\
\hline Were complications of disease explained:: Frequency [\%] & & 7 \\
\hline Yes & $|3|[70.8 \%]$ & \\
\hline No & 54 [29.2\%] & \\
\hline Was the physician able to answer your queries about inherited blood disorders: Frequency [\%] & & 11 \\
\hline Yes & $142[78.5 \%]$ & \\
\hline No & $39[21.5 \%]$ & \\
\hline What educational material was provided during counselling session*: Frequency [\%] & & 18 \\
\hline No supplementary materials were provided & $82[47.1 \%]$ & \\
\hline Video & $21[12.1 \%]$ & \\
\hline Booklets & 25 [14.4\%] & \\
\hline Pamphlets & $26[14.9 \%]$ & \\
\hline Posters & $20[11.5 \%]$ & \\
\hline Why did you refused the counselling advice and proceed with marriage*: Frequency [\%] & & 7 \\
\hline Refused because our marriage was unavoidable destiny & $100[52 \%]$ & \\
\hline Refused because the chance of transmission of inherited disease was small & $35[18.2 \%]$ & \\
\hline Refused because of the relationship between the couple & $29[15.1 \%]$ & \\
\hline Refused because financial marriage arrangements were completed before premarital test & $22[7.8 \%]$ & \\
\hline Refused because the counselling was not convincing & $14[7.3 \%]$ & \\
\hline Refused because inherited blood disorders do not affect children's lives & $10[5.2 \%]$ & \\
\hline Refused counselling advice since I was in love with my fiancé & 9 [4.6\%] & \\
\hline Refused counselling advice due to pressure of my family & 7 [3.6\%] & \\
\hline Refused counselling advice to avoid being lonely & 7 [3.6\%] & \\
\hline Refused counselling advice due to not realising the seriousness of the inherited blood disorders & $3[1.5 \%]$ & \\
\hline
\end{tabular}

Note: *Parents were able to choose more than one answer. 
marriage expenses before the premarital counselling, being in love with their partners, being forced to proceed with the marriage, or the avoidance of loneliness.

\section{Discussion}

This study was a cross-sectional investigation targeting subjects in the Jazan region who, with their partners, were identified as high-risk couples and proceeded with their marriages. The majority of the respondents had been through higher education and were employed. The majority of the respondents were related to their partners and were carriers of sickle cell disease. More than 60 respondents believed that inherited blood disorders were not prevalent in the Jazan region and that they would advise other high-risk couples to proceed with their marriage. Physicians and healthcare workers came second to the Internet as sources of information about hemoglobinopathies. The median duration of the premarital counselling sessions was 10 minutes and the belief that marriage was one's unavoidable destiny was the most frequently reported reason for ignoring the premarital counselling advice.

The findings of this study can be compared to other national investigations measuring the factors associated with the decisions of high-risk couples to proceed with marriage. A study by Alswaidi et al assessed the factors associated with the decision to proceed with marriage among 934 couples identified as high-risk couples between 2005 and 2006. Among the high-risk couples identified in the study, $88.2 \%$ of them ignored the results of the premarital testing and proceeded with the marriage. ${ }^{15}$ In their investigation, a comparison of demographics between those who opted to proceed with the marriage and those who cancelled their marriage plans indicated no statistically significant differences in age, gender, education or source of income. Although our investigation included one group, and no comparison was made with individuals who opted to cancel their marriage proposals, it was noted that the majority of the respondents were educated and employed. This may suggest that demographic factors related to age, gender, education and employment do not have a strong influence on the decision to proceed with marriage proposals among high-risk couples in Saudi Arabia.

Our findings suggest that cultural and financial factors could have a stronger influence on the decision of highrisk couples to proceed with marriage. This fact was identified in the study by Alswaidi et al where the inability to cancel planned weddings and fear of social stigma were the main reasons behind proceeding with marriage among high-risk couples. ${ }^{15}$ Similarly, in a smaller study by AlSulaiman et al targeting 129 subjects identified as highrisk individuals who proceeded with marriage to their partners, cultural factors were reported as the leading factor behind proceeding with the marriage. ${ }^{14}$ This finding is similar to our own, indicating the impact of culture and beliefs in forcing high-risk couples to proceed with their marriages.

One of the factors that seemed to force identified couples at risk of having children with hemoglobinopathies to proceed with their marriage plans was having a relationship (consanguinity). About $67 \%$ of the respondents to our survey were related to their partners, and this consanguinity between the couples was one of the leading reasons behind the rejection of premarital counselling advice. This finding is similar to the findings of Alswaidi et al, where the proportion of high-risk couples with a history of consanguinity was higher among couples who opted to proceed with the marriage in comparison to those who decided not to marry. ${ }^{15}$

Although data concerning the proportion of identified high-risk couples in the Jazan region who opted to proceed with marriage or cancelled their marriage proposals are not publicly available, the findings of our investigation suggest a limited influence of the premarital counselling advice in creating a healthier practice among identified high-risk couples towards the cancellation of their marriage plans. This notion is supported by observations related to the short duration of counselling sessions, the limited use of educational materials, and the limited awareness among some attendees of the risks and the clinical ramifications of having children affected by hemoglobinopathies. Although the study by Alswaidi et al was conducted before the production of the Counselling Clinic Guidelines for Premarital Screening via the Saudi Ministry of Health in 2015, they did measure the attendance of identified high-risk couples of premarital counselling sessions. Upon comparing the proportion of individuals who attended the premarital counselling between those who opted to cancel their marriage and those who proceeded with their marriage plans, it was reported that there was no difference between the two comparison groups, suggesting the limited influence of the counselling. ${ }^{15}$

The findings of this study can be compared to similar Arab and Mediterranean countries. In a study conducted in 
Morocco recruiting the parents of 197 children diagnosed with hemoglobinopathies, it was reported that $50.25 \%$ of the sample of parents were related to their partners. ${ }^{16}$ This finding is similar to our findings, illustrating the important cultural influence in supporting consanguineous marriages.

Religious and cultural factors can influence the effectiveness of screening for haemoglobinopathies. In a Greek study, a total of 116 pregnancies were screened for haemoglobinopathies between 2002 and 2006 and 100 were identified as a pregnancy with the risk of giving birth to a child affected by hemoglobinopathies. After providing antenatal counselling, all counselled couples opted to terminate the pregnancies. ${ }^{17}$ In a similar Indian study, 85 pregnancies were identified as risky for hemoglobinopathies and were all terminated after counselling. ${ }^{18}$ However, the termination of pregnancies is mostly not permitted in Saudi Arabia and can be considered an unlawful action, which explains the persistence of the incidence of births affected by hemoglobinopathies. Finally, in a review assessing the effectiveness of premarital screening and genetic counselling programmes in eight Middle East countries when it came to reducing at-risk marriages, it was concluded that in countries not permitting prenatal detection and abortion, the premarital screening programmes were not successful in reducing the prevalence of affected births. ${ }^{19}$

Premarital screening and counselling services provided within the healthy marriage program are provided in governmental healthcare establishments. Giving the cultural and religious aspects influencing effectiveness of premarital counselling identified in our investigation, considering benefiting from contribution of community leaders and religious establishments may have a positive impact on increasing counselling effectiveness. This notion was indicated in Nigerian studies targeting mothers attending antenatal care clinics ${ }^{20}$ and males in a semi-urban community. ${ }^{21}$ In both studies, majority of the respondents reported attending counselling sessions in churches, which illustrates the importance of involving religious establishments in raising the awareness about premarital screening for sickle cell disease. Nonetheless, Aneke and Okocha questioned the quality and effectiveness of counselling offered by religious bodies in Nigeria and emphasized on the importance of creating strong partnership between healthcare and religious establishments. ${ }^{22}$ Creation of this partnership can be applicable in Saudi Arabian settings to increase the effectiveness of genetic counselling services giving the strong cultural and religious influence in the Saudi community.

\section{Strengths and Limitations}

This study has multiple strengths and weaknesses. It utilised an open-ended approach to identify the factors behind the limited effectiveness of premarital counselling in the Jazan region, such as factors related to the counselling services or cultural factors related to the community. The main limitation of this study relates to the probability of selection bias, due to utilising a web-based questionnaire. However, having respondents from different demographic backgrounds may indicate good participation from the targeted population.

\section{Conclusion}

The study findings indicate a strong cultural influence leading to the reduced effectiveness of premarital counselling in the Jazan region. These cultural factors are related to believing that mating between high-risk couples is an unavoidable destiny. This perception can be explained by religious beliefs. Another cultural factor is related to consanguinity and forced marriages imposed by family pressures. Finally, other factors are related to the limited influence of the counselling service in raising the awareness of attendees regarding the impact of hemoglobinopathies on the lives of children affected. These findings suggest a need to improve the premarital counselling service in the south of Saudi Arabia and to involve public figures and community leaders in the process of modifying cultural and religious beliefs with regard to at-risk marriages in the region. Furthermore, more investigations should conducted to evaluate factors influencing the quality of counselling services provided in premarital counselling clinic, especially, with regard to qualifications, and training of healthcare professional who are providing the counselling and the available infrastructure.

\section{Author Contributions}

All authors contributed to data analysis, drafting or revising the article, have agreed on the journal to which the article will be submitted, gave final approval of the version to be published, and agree to be accountable for all aspects of the work.

\section{Funding}

This research did not receive any specific grant from any funding agency. 


\section{Disclosure}

The authors reported no conflicts of interest for this work.

\section{References}

1. Telfer P, Coen PG, Christou S, et al. Survival of medically treated thalassemia patients in Cyprus. Trends and risk factors over the period 1980-2004. Haematologica. 2006;91(9):1187-1192.

2. Fleming AF, Storey J, Molineaux L, Iroko EA, Attai EDE. Abnormal haemoglobins in the Sudan savanna of Nigeria. I. Prevalence of haemoglobins and relationships between sickle cell trait, malaria and survival. Ann Trop Med Parasitol. 1979;73(2):161-172. doi:10.1080/00034983.1979.11687243

3. Modell B, Darlison M. Global epidemiology of haemoglobin disorders and derived service indicators. Bull World Health Organ. 2008;86(6):480-487. doi:10.2471/BLT.06.036673

4. Borgna-Pignatti C, Gamberini MR. Complications of thalassemia major and their treatment. Expert Rev Hematol. 2011;4(3):353-366. doi:10.1586/ehm.11.29

5. Centre for Disease Control. Complications and Treatments of Sickle Cell Disease; 2020. Available from: https://www.cdc.gov/ncbddd/sick lecell/treatments.html. Accessed August 11, 2020.

6. Badawi MA, Adam S, Ghoneim A, et al. Clinical Complications of Hemoglobinopathies in Western Saudi Arabia and the Need for Specialized Care Centers. J King Abdulaziz Univ Med Sci. 2019;26 (1):8. doi:10.4197/Med.26-1.5

7. El-Hazmi MA. The natural history and the national pre-marital screening program in Saudi Arabia. Saudi Med J. 2004;25 (11):1549-1554.

8. Gosadi IM. National screening programs in Saudi Arabia: overview, outcomes, and effectiveness. J Infect Public Health. 2019;12 (5):608-614. doi:10.1016/j.jiph.2019.06.001

9. Al-Shroby WA, Sulimani SM, Alhurishi SA, Bin Dayel ME, Alsanie NA, Alhraiwil NJ. Awareness of Premarital Screening and Genetic Counseling among Saudis and its Association with Sociodemographic Factors: a National Study. J Multidiscip Healthc. 2021;14:389-399. doi:10.2147/JMDH.S296221

10. Memish ZA, Saeedi MY. Six-year outcome of the national premarital screening and genetic counseling program for sickle cell disease and $\beta$-thalassemia in Saudi Arabia. Ann Saudi Med. 2011;31(3):229-235. doi:10.4103/0256-4947.81527

11. Saudi Ministry of Health. Counselling Clinic Guidelines for Premarital Screening; 2015. Available from: https://www.moh.gov.sa/Ministry/ About/Health\%20Policies/004.pdf. Accessed August 11, 2020.
12. Memish ZA, Owaidah TM, Saeedi MY. Marked regional variations in the prevalence of sickle cell disease and $\beta$-thalassemia in Saudi Arabia: findings from the premarital screening and genetic counseling program. J Epidemiol Glob Health. 2011;1(1):61-68. doi:10.1016/j. jegh.2011.06.002

13. Hamali HA, Saboor M. Undiagnosed Hemoglobinopathies: a potential threat to the premarital screening program. Pak J Med Sci. 2019;35(6):1611-1615. doi:10.12669/pjms.35.6.976

14. Al Sulaiman A, Saeedi M, Al Suliman A, Owaidah T. Postmarital follow-up survey on high risk patients subjected to premarital screening program in Saudi Arabia. Prenat Diagn. 2010;30(5):478-481. doi:10.1002/pd.2507

15. Alswaidi FM, Memish ZA, O'Brien SJ, et al. At-risk marriages after compulsory premarital testing and counseling for $\beta$-thalassemia and sickle cell disease in Saudi Arabia, 2005-2006. J Genet Couns. 2012;21(2):243-255. doi:10.1007/s10897-011-9395-4

16. Laghmich A, Alaoui Ismaili FZ, Zian Z, Barakat A, Ghailani Nourouti N, Bennani Mechita M. Hemoglobinopathies in the North of Morocco: consanguinity Pilot Study. Biomed Res Int. 2019;2019:6857417. doi:10.1155/2019/6857417

17. Theodoridou S, Alemayehou M, Prappas N, et al. Carrier screening and prenatal diagnosis of hemoglobinopathies. A study of indigenous and immigrant couples in northern Greece, over the last 5 years. Hemoglobin. 2008;32(5):434-439. doi:10.1080/03630260802341745

18. Colah R, Surve R, Nadkarni A, et al. Prenatal diagnosis of sickle syndromes in India: dilemmas in counselling. Prenat Diagn. 2005;25 (5):345-349. doi:10.1002/pd.1131

19. Saffi M, Howard N. Exploring the Effectiveness of Mandatory Premarital Screening and Genetic Counselling Programmes for $\beta$ Thalassaemia in the Middle East: a Scoping Review. Public Health Genomics. 2015;18(4):193-203. doi:10.1159/000430837

20. Ezechukwu CC, Egbuonu L, Chukwuka JO. Pre-marriage counseling as a tool for sickle cell disease awareness in Nigerians. Sahel Med J. 2004;7(2):4. doi:10.4314/smj2.v7i2.12868

21. Gbeneol PK, Brisibe SF, Knowledge OB. Attitude and Uptake of Premarital Screening for the Sickle Trait Among Married Couples in a Semi-Urban Community in South-South Nigeria. Eur J Prevent Med. 2015;3(3):6.

22. Aneke J, Okocha C. Sickle cell disease genetic counseling and testing: a review. Arch Med Health Sci. 2016;4(1):50-57. doi:10.4103/ 2321-4848.183342
International Journal of General Medicine

\section{Publish your work in this journal}

The International Journal of General Medicine is an international, peer-reviewed open-access journal that focuses on general and internal medicine, pathogenesis, epidemiology, diagnosis, monitoring and treatment protocols. The journal is characterized by the rapid reporting of reviews, original research and clinical studies across all disease areas. The manuscript management system is completely online and includes a very quick and fair peer-review system, which is all easy to use. Visit http://www.dovepress.com/ testimonials.php to read real quotes from published authors. 